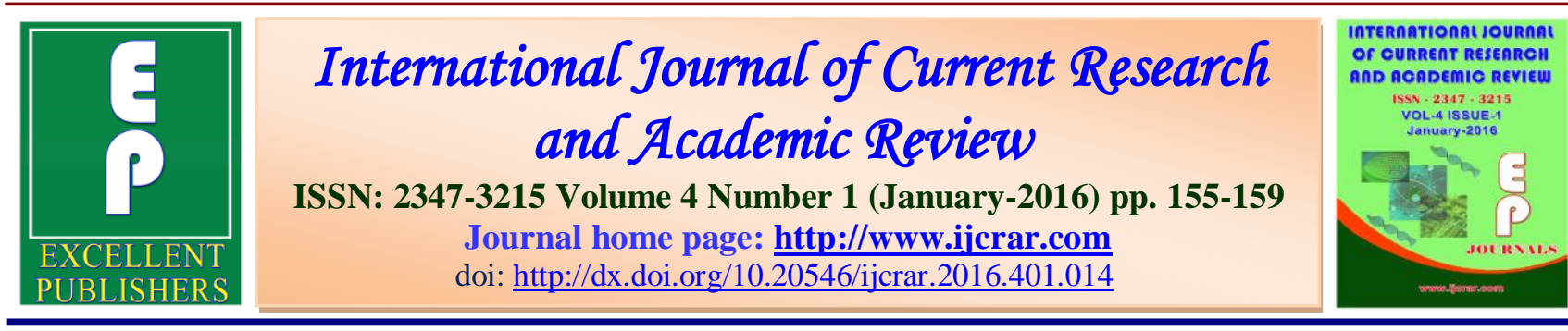

\title{
Potential of Linalool for Inhibition of Cassia occidentalis
}

\author{
Supriya Vaid*
}

Department of Botany, MCM DAV College for Women, Sector 36, Chandigarh, 160036, India

*Corresponding author

\section{KEYWORDS}

Inhibition,

Cassia

occidentalis,

volatile

monoterpene,

linalool,

chlorophyll

content,

cellular

respiration

\section{A B S T R A C T}

A study was carried out to assess the inhibitory potential of linalool, a volatile monoterpene found in many flowers and spice plants against coffee-weed, Cassia occidentalis. Linalool was found to have a significant inhibitory effect on the germination and early seedling growth of the test weed. The germination in the test weed was reduced by about $17 \%$ at the lowest concentration of $0.2 \mathrm{nl} / \mathrm{cc}$ and a complete germination inhibition was observed at $20 \mathrm{nl} / \mathrm{cc}$ linalool treatment. Similarly, the seedling growth of the test weed in terms of radicle length, seedling length and seedling dry weight was appreciably reduced in response to various increasing concentrations of linalool. Likewise, the physiological parameters viz. the content of total chlorophyll and percent cellular respiration of the test weed were also reduced to varying degrees compared to control, indicating a negative effect of the test monoterpene on the photosynthetic efficiency and energy metabolism of the weed species. Based on the above study, it is concluded that linalool possesses weed-suppressing abilities and can be employed for the management of obnoxious weeds.

\section{Introduction}

Volatile monoterpenes, the constituents of essential oils, are the simplest chemical molecules belonging to the terpenoid family and possess multiple biological and ecological functions. Because of their natural aroma, they find extensive use in food, perfumery, cosmetic industries and aromatherapy. They also play many important roles including plant-plant interactions, defense mechanism as plant protectants against herbivory and as pollinator-attractants and thus help in maintaining the delicate balance of ecosystems (Swain, 1977; Fischer, 1991; Vokou, 1999; Paiva, 2000). As potent inhibitors of seed germination, these monoterpenes are involved in allelopathic interactions among plants and thus play an important role in maintaining, structuring and patterning of plant communities in 
natural ecosystems (Muller, 1965; Asplund, 1968; Abrahim et al., 2000; Singh et al., 2002a, b; Weidenhamer et al., 1993; Vokou, 1999). Besides this, they are easily biodegradable and possess little toxicity against mammals and other non-target species. These properties make these chemicals immensely suitable for agroindustry (Isman, 2000; Beuchat, 2001). Some studies have already reported their use as potential chemicals for the management of weeds and pests in sustainable agriculture (Isman, 2000; Romagni et al., 2000; Singh et al., 2002a, b).

Various monoterpenes like citronellal, citronellol and cineole have been observed to inhibit germination and initial seedling growth of several weeds such as Amaranthus viridis, Echinochloa crus-galli and Bidens pilosa under in vitro conditions (Singh et al., 2002b, 2004). Linalool is a monoterpene present in a number of flower and spice plants like Lavandula officinalis, Thymus vulgaris, Ocimum basilicum, Cinnamomum tamala, Artemisia vulgaris and Cannabis sativa. Inspite of abundant availability and high phytotoxicity, the potential of linalool as a bio-herbicide still remains to be investigated.

The present investigation was therefore undertaken to explore the phytotoxic effect of linalool against a weedy species, Cassia occidentalis with a view to explore its herbicidal potential.

\section{Materials and Methods}

\section{Collection of Materials}

Seeds of Coffee weed (Cassia occidentalis L.) were collected locally from wildly growing stands in the campus of Panjab University, Chandigarh. Linalool was purchased from Lancaster, UK. The seeds were surface sterilized.

\section{Bioassay Studies}

Seeds of Cassia occidentalis were divided into 9 groups of 50 each and dipped in distilled water for $16 \mathrm{~h}$ for imbibition prior to germination trials. These were then equidistantly placed in 6" diameter Petri dishes lined with two layers of moistened Whatman no. 1 filter paper. The treatment of linalool was given in concentrations ranging from $0.2,1,1.5,2,5,10,15$ and $20 \mathrm{nl} / \mathrm{cc}$ volume of Petri dishes. After the addition of the volatile monoterpene, the Petri dishes were properly sealed. A similar set-up without the treatment of linalool served as control. For each treatment, 5 replicates were maintained. The entire set up was kept in an environmentally controlled seed germinating chamber at $25 \pm 2{ }^{\circ} \mathrm{C}$ and $75 \pm$ $2 \%$ relative humidity with a photoperiod of $16 / 8$ day/night. After a week, the number of seeds that germinated was counted, radicle length, seedling length and seedling dry weight were measured and the total chlorophyll content and percent respiratory activity were determined.

\section{Estimations}

Chlorophyll was extracted from $25 \mathrm{mg}$ of tissue in $4 \mathrm{ml}$ of Dimethyl sulphoxide (DMSO) following Hiscox and Israelstam (1979). The extinction values of chlorophyll thus recovered in DMSO were measured at dual wavelengths of $645 \mathrm{~nm}$ and $663 \mathrm{~nm}$ on Shimadzu Spectrophotometer using DMSO as blank. Total chlorophyll content was calculated from extinction values following the equation of (Arnon, 1949) and expressed on dry weight basis as per Rani and Kohli (1991). Values on dry weight equivalents were calculated by placing same amount of tissue in an oven at $80^{\circ} \mathrm{C}$ for $24 \mathrm{hr}$.

Respiratory values were determined from the fresh plant tissue indirectly using 2,3,5- 
triphenyl tetrazolium chloride following the method of Steponkus and Lanphear (1967). This is an indirect measure of cellular respiration whereby formation of red coloured formazan occurs due to trapping of the oxygen molecules released through the respiratory chain. The values of treated samples thus obtained were expressed as percent cellular respiration with respect to control.

\section{Statistical Analysis}

The data of percent germination, radicle length, seedling length, seedling dry weight, chlorophyll content and respiratory activity was analyzed by one-way ANOVA followed by Duncan's multiple range test.

\section{Results and Discussion}

It is very clear from the results that in response to linalool, germination of Cassia occidentalis was reduced to varying degrees depending upon the concentration of the former (Table 1). At the lowest concentration of $0.2 \mathrm{nl} / \mathrm{cc}$ linalool treatment, germination was reduced by about $17 \%$ while at $15 \mathrm{nl} / \mathrm{cc}$, a reduction of over $60 \%$ was observed. A complete inhibition of germination of the test weed was observed at a concentration of $20 \mathrm{nl} / \mathrm{cc}$. Similarly, the radicle length of the test weed was also significantly reduced in response to the monoterpene. At $1 \mathrm{nl} / \mathrm{cc}$ treatment, radicle length was reduced to about $83 \%$ while it was reduced to $41 \%$ at $15 \mathrm{nl} / \mathrm{cc}$ compared to control (Table 1).

Further, seedling growth measured in terms of seedling length and seedling dry weight of the test weed was also significantly reduced compared to control (Table 2). At $0.2 \mathrm{nl} / \mathrm{cc}$ treatment, seedling length was reduced by $11 \%$ while it was reduced by about $63 \%$ at $15 \mathrm{nl} / \mathrm{cc}$ compared to control.
At the concentration of $1 \mathrm{nl} / \mathrm{cc}$ linalool treatment, seedling dry weight was reduced by about $17 \%$ while at $15 \mathrm{nl} / \mathrm{cc}$, a reduction of about $45 \%$ was observed. The observed inhibition of germination and initial growth of the weedy species could be due to the disruption of mitotic activity in the germinating seeds.

This is strengthened by references available in literature (Romagni et al., 2000). Several reasons have been put forward to determine the factors that disrupt mitosis including disruption of microtubule organization or alternation of cell wall biosynthesis (Lehnen and Vaughn, 1992).

Likewise, the content of chlorophyll was significantly less in linalool-treated samples compared to control. At the lowest concentration of $0.2 \mathrm{nl} / \mathrm{cc}$, chlorophyll content was reduced by about $23 \%$ while at $15 \mathrm{nl} / \mathrm{cc}$, a reduction of around $62 \%$ was observed (Table 3). The decrease in chlorophyll content points towards the diminishing photosynthetic efficiency in response to the test monoterpene. The mechanism behind the decrease in chlorophyll content in the target weed (whether it is due to its decreased synthesis or enhanced degradation) could not be ascertained from the present study. However, references available in literature indicate reduction in the levels of chlorophyll pigment in response to allelochemicals (Romagni et al., 2000; Singh et al., 2002b).

An appreciable reduction in cellular respiration was also observed in $C$. occidentalis when treated with linalool (Table 3). At the lowest concentration of 0.2 $\mathrm{nl} / \mathrm{cc}$, cellular respiration was reduced by about $13 \%$ while at $15 \mathrm{nl} / \mathrm{cc}$, a reduction of around $85 \%$ was observed. 
Int.J.Curr.Res.Aca.Rev.2016; 4(1): 155-159

Table.1 Effect of Linalool on the Percent Germination and Radicle Length (cm) of $C$. occidentalis

\begin{tabular}{|c|c|c|}
\hline Concentration (nl/cc) & Percent Germination & Radicle Length (cm) \\
\hline $\mathbf{0}$ & $\mathbf{1 0 0} \pm 0^{\mathrm{a}}$ & $\mathbf{4 . 6 2} \pm 0.2^{\mathrm{a}}$ \\
\hline $\mathbf{0 . 2}$ & $\mathbf{8 3 . 3 3} \pm 11.55^{\mathrm{b}}$ & $\mathbf{4 . 1 8} \pm 0.31(90.48)^{\mathrm{b}}$ \\
\hline $\mathbf{1}$ & $\mathbf{7 3 . 3 3} \pm 10.23^{\mathrm{c}}$ & $\mathbf{3 . 8 3} \pm 0.09(82.90)^{\mathrm{c}}$ \\
\hline $\mathbf{1 . 5}$ & $\mathbf{6 4 . 2 1} \pm 10.08^{\mathrm{d}}$ & $\mathbf{3 . 4 2} \pm 0.11(74.03)^{\mathrm{d}}$ \\
\hline $\mathbf{2}$ & $\mathbf{5 6 . 6 7} \pm 5.77^{\mathrm{d}}$ & $\mathbf{3 . 0 9} \pm 0.03(66.88)^{\mathrm{d}}$ \\
\hline $\mathbf{1 0}$ & $\mathbf{4 6 . 5 6} \pm 4.78^{\mathrm{f}}$ & $\mathbf{2 . 5 3} \pm 0.04(54.76)^{\mathrm{e}}$ \\
\hline $\mathbf{1 5}$ & $\mathbf{4 3 . 3 3} \pm 6.55^{\mathrm{f}}$ & $\mathbf{2 . 1 6} \pm 0.06(46.75)^{\mathrm{f}}$ \\
\hline $\mathbf{2 0}$ & $\mathbf{3 6 . 6 7} \pm 5.85^{\mathrm{g}}$ & $\mathbf{1 . 9} \pm 0.09(41.13)^{\mathrm{g}}$ \\
\hline & - & - \\
\hline
\end{tabular}

Different superscripts in a column represent significant difference at $\mathrm{P}<0.05$.

Table.2 Effect of Linalool on the Seedling Length $(\mathrm{cm})$ and Seedling Dry Weight (mg) of C. occidentalis

\begin{tabular}{|c|c|c|}
\hline Concentration (nl/cc) & Seedling Length (cm) & Seedling Dry Weight (mg) \\
\hline $\mathbf{0}$ & $\mathbf{1 1 . 7} \pm 0.27^{\mathrm{a}}$ & $\mathbf{1 1 . 3 9} \pm 0.08$ \\
\hline $\mathbf{0 . 2}$ & $\mathbf{1 0 . 4 0} \pm 0.31(88.89)^{\mathrm{b}}$ & $\mathbf{1 0 . 9 2} \pm 0.18(95.87)^{\mathrm{b}}$ \\
\hline $\mathbf{1}$ & $\mathbf{9 . 5} \pm 0.12(81.20)^{\mathrm{c}}$ & $\mathbf{9 . 5} \pm 0.12(83.41)^{\mathrm{c}}$ \\
\hline $\mathbf{1 . 5}$ & $\mathbf{8 . 8 1} \pm 0.07(75.30)^{\mathrm{d}}$ & $\mathbf{9 . 2 8} \pm 0.35(81.47)^{\mathrm{c}}$ \\
\hline $\mathbf{2}$ & $\mathbf{8 . 1 1} \pm 0.05(69.32)^{\mathrm{e}}$ & $\mathbf{8 . 2 2} \pm 1.23(72.17)^{\mathrm{d}}$ \\
\hline $\mathbf{5}$ & $\mathbf{7 . 1 6} \pm 0.35(61.20)^{\mathrm{f}}$ & $\mathbf{7 . 2 8} \pm 0.16(63.92)^{\mathrm{e}}$ \\
\hline $\mathbf{1 0}$ & $\mathbf{6 . 2 8} \pm 0.11(53.68)^{\mathrm{g}}$ & $\mathbf{6 . 9 2} \pm 0.05(60.76)^{\mathrm{f}}$ \\
\hline $\mathbf{1 5}$ & $\mathbf{4 . 3 2} \pm 0.34(36.92)^{\mathrm{h}}$ & $\mathbf{6 . 3} \pm 0.24(55.31)^{\mathrm{g}}$ \\
\hline $\mathbf{2 0}$ & - & - \\
\hline
\end{tabular}

Different superscripts in a column represent significant difference at $\mathrm{P}<0.05$.

Table.3 Effect of Linalool on the Total Chlorophyll Content $(\mu \mathrm{g} / \mathrm{mg})$ and Percent Cellular Respiration of $C$. occidentalis

\begin{tabular}{|c|c|c|}
\hline $\begin{array}{c}\text { Concentration } \\
(\mathbf{n l} / \mathbf{c c})\end{array}$ & $\begin{array}{c}\text { Total Chlorophyll Content } \\
(\boldsymbol{\mu g} / \mathbf{m g})\end{array}$ & $\begin{array}{c}\text { Percent Cellular } \\
\text { Respiration }\end{array}$ \\
\hline $\mathbf{0}$ & $\mathbf{8 . 7 2} \pm 0.13^{\mathrm{a}}$ & $\mathbf{1 0 0} \pm 1.23^{\mathrm{a}}$ \\
\hline $\mathbf{0 . 2}$ & $\mathbf{6 . 7 5} \pm 0.04(77.41)^{\mathrm{b}}$ & $\mathbf{8 6 . 7 0} \pm 1.9^{\mathrm{b}}$ \\
\hline $\mathbf{1}$ & $\mathbf{6 . 5 9} \pm 0.04(75.57)^{\mathrm{b}}$ & $\mathbf{7 1 . 3 6} \pm 1.54^{\mathrm{c}}$ \\
\hline $\mathbf{1 . 5}$ & $\mathbf{6 . 5 3} \pm 0.05(74.89)^{\mathrm{b}}$ & $\mathbf{4 9 . 8 0} \pm 0.76^{\mathrm{d}}$ \\
\hline $\mathbf{2}$ & $\mathbf{6 . 1 7} \pm 0.08(70.76)^{\mathrm{c}}$ & $\mathbf{4 6 . 2 1} \pm 1.01^{\mathrm{d}}$ \\
\hline $\mathbf{5}$ & $\mathbf{5 . 4 3} \pm 0.09(62.27)^{\mathrm{d}}$ & $\mathbf{4 0 . 6 7} \pm 1.54^{\mathrm{e}}$ \\
\hline $\mathbf{1 0}$ & $\mathbf{3 . 8 0} \pm 0.07(43.58)^{\mathrm{e}}$ & $\mathbf{2 4 . 5 0} \pm 0.76^{\mathrm{f}}$ \\
\hline $\mathbf{1 5}$ & $\mathbf{3 . 3 2} \pm 0.02(38.03)^{\mathrm{f}}$ & $\mathbf{1 5 . 7 9} \pm 1.25^{\mathrm{g}}$ \\
\hline $\mathbf{2 0}$ & - & - \\
\hline
\end{tabular}

Different superscripts in a column represent significant difference at $\mathrm{P}<0.05$.

\section{Conclusion}

It is clear from the present study that linalool has a potential to reduce the germination, early growth and development of the weed species and thus could prove very useful for future weed management programmes either directly or by serving as a lead molecule. 


\section{References}

Abrahim D., Braguini W. L., Kelmer-Bracht A. M, and Ishii-Iwamoto E. L. (2000). Effects of four monoterpenes on germination, primary root growth, and mitochondrial respiration of maize. J. Chem. Ecol. 26: 611-624.

Arnon D. I. (1949). Copper enzymes in isolated chloroplasts: Polyphenol oxidase in Beta vulgaris. Plant Physiol. 24: 1-15.

Asplund R. O. (1968). Monoterpenes: relationship between structure and inhibition of germination. Phytochemistry 7: 1995-1997.

Beuchat L. R. (2001). Control of food borne pathogens and spoilage microorganisms by naturally occurring antimicrobials. In: Microbial Food Contamination (Wilson C. L. and Droby S., eds.). CRC Press, Boca Raton, FL, pp. 149-169.

Fischer N. H. (1991). Plant terpenoids as allelopathic agents. In: Ecological Chemistry and Biochemistry of Plant Terpenoids (Harborne J. B. and TomasBar-beran F. A., eds.). Clarendon Press, Oxford, pp. 377-399.

Hiscox T. D. and Israelstam G. F. (1979). A method for extraction of chlorophyll from leaf tissue without maceration. Can. J. Bot. 57: 1332-1334.

Isman M. B. (2000). Plant essential oils for pest and disease management. Crop Prot. 19: 603-608.

Lehnen L. P. Jr. and Vaughn K. C. (1992). The herbicide sindone $\mathrm{B}$ disrupts spindle microtubule organising centres. Pestic. Biochem. Physiol. 44:50-59.

Muller C. H. (1965). Inhibitory terpenes volatilized from Salvia shrubs. Bull. Torr. Bot. Club 91: 327-330.

Paiva N. L. (2000). An introduction to the biosynthesis of the chemicals used in plant- microbe communication. J. Plant Growth Regul. 19: 131-143.

Rani D. and Kohli R. K. (1991). Fresh matter is not an appropriate unit for chlorophyll content: experiences from experiments on effects of herbicides and allelopathic substances. Photosynthetica 25: 655-658.

Romagni J. G., Allen S. N., and Dayan F. E. (2000). Allelopathic effects of volatile cineoles on two weedy plant species. J. Chem. Ecol. 26: 303-313.

Singh H. P., Batish D. R., and Kohli R. K. (2002a). Allelopathic effects of two volatile monoterpenes against bill goat weed (Ageratum conyzoides L.). Crop Prot. 21: 347-350.

Singh H. P., Batish D. R., Kaur S., Ramezani H., and Kohli R. K. (2002b). Comparative phytotoxicity of four monoterpenes against Cassia occidentalis. Ann. Appl. Biol. 141: 111-116.

Singh H. P., Batish D. R., Kaur S., Vaid S., and Kohli R. K. (2004). Weed suppressing ability of some volatile monoterpenes. J. Plant Dis. Prot. XIX: 821-828.

Steponkus P. L. and Lanphear F. R. (1967). Refinement of triphenyl tetrazolium chloride method of determining cold injury. Plant Physiol. 42: 1423-1426.

Swain T. (1977). Secondary compounds as protective agents. Annu. Rev. Plant Physiol. 28: 479-501.

Vokou D. (1999). Essential oils as allelochemicals: research advances in Greece. In: Allelopathy Update, Vol. 2. Basic and Applied Aspects (Narwal S. S., ed.). Science Publishers, New York, pp. 4763.

Weidenhamer J. D., Macias F. A., Fischer N. H., and Williamson G. B. (1993). Just how insoluble are monoterpenes? J. Chem. Ecol. 19: 1799-1807.

\section{How to cite this article:}

Supriya Vaid. 2016. Potential of Linalool for Inhibition of Cassia occidentalis. Int.J.Curr.Res.Aca.Rev. 4(1): 155-159. doi: http://dx.doi.org/10.20546/ijcrar.2016.401.014 